\title{
WIKI AND BLOG AS TEACHING TOOLS IN TOURISM HIGHER EDUCATION
}

\author{
Adelaida Lillo-Bañuls \\ José Francisco Perles-Ribes \\ Ramón Fuentes \\ Department of Applied Economic Analysis and Tourism \\ Research Institute, University of Alicante (Spain)
}

\begin{abstract}
Adelaida Lillo-Bañuls
Department of Applied Economic Analysis, University of Alicante, E-03080, Spain.

Corresponding author. E-mail adress: alillo@ua.es (Lillo-Bañuls, A.).
\end{abstract}

Others authors email adress: jfperles@gmail.com rfuentes@ua.es

\begin{abstract}
:
The application of Information and Communications Technologies (ICTs) to higher education is an essential element in the improvement of open and flexible teaching-learning. This is particularly important for students of Tourism, a sector in which the relationship with technological processes and their every-day use is increasing. This article describes the experience of teaching staff involved in this initiative based on the information provided by lecturers, a student quantitative survey and qualitative aspects in order to obtain the start profile of the tourism students, including their family background, gender differences and the attitude of students towards use of new technologies as an educational tool.
\end{abstract}




\section{1.-INTRODUCTION}

The key role that education and training plays in the competitive strategies of the tourism sector is an idea widely accepted by the various agents that make up the tourism industry. The efficiency with which new management methods are incorporated, or with which new technologies are employed in tourism companies, also requires more highly educated workers (Lillo-Bañuls, 2009).

This study analyses the educational technological tools introduced and the main results of this experience. In particular, it describes the experience of how teaching staff introduced this innovation, basically consisting of creating a wiki (WikiTur) and a blog (BlogTur) through which students were able to contribute to the different topics covered in the subject "An Introduction to Economics", taught as part of the Tourism Diploma course. Based on the information provided by the teaching staff, and data obtained through a student survey, the results of this experience were analysed in order to identify the positive aspects and to define possible changes that could improve future use of technological resources in teaching this subject.

A first step towards achieving the teaching objectives related to new Information and Communications Technologies (ICTs) was the introduction of students' assiduous use of a wiki (WikiTur) and a blog (BlogTur) to which they contributed their views on the different topics covered by the Economics 
subject as part of the Tourism Degree course. The main purpose of selecting a wiki and a blog as technological educational tools was that the teacher could provide the specific controlled link and also allow pages to be edited by the multiple participants sharing the content. Furthermore, students were already aware of such tools and were familiar with them.

This study examines the relations between technology and education and the need to incorporate different educational technological innovations into the teaching of economics within the Tourism Degree. The teaching-learning process carried out with the wiki and the blog is also described.

This educational research analyses the results of the initial experience set up by the group of lecturers incorporating the daily use of the blog and the wiki in order to highlight any positive aspects discovered and to discover any modifications needed to improve this use of technological resources for teaching tourism in future.

The final section describes a quantitative analysis of an extensive and detailed survey carried out among the students on their technological skills and internet use, access to the University and grants, the time spent studying the subject, family educational background and a numerical evaluation of the technological tools used (wiki and blog). Some qualitative questions about the use of wiki and blog were also asked in order to reinforce and underpin the results.

Finally, the main conclusions drawn from the study are presented, with some reflections regarding teaching innovation in higher education and future strategies.

\section{2.-RELATING NEW ICTs AND TOURISM EDUCATION}

The application of new technologies to higher education is essential for improving open and flexible teaching-learning processes involving the use of virtual tools and technological processes. ICTs have an impact on the role and competences of teachers (Volman 2005). Noteborn, Dailey-Hebert; Bohle and Gijselaers (2014) highlight the fact that while content knowledge is important, in today's job 
market, graduates need to develop procedural knowledge and transferable skills as new technologies continue to emerge.

This is particularly important for students of Tourism, a sector in which the relationship with technological and IT processes and their every-day use is increasingly necessary (Buhalis and Law 2008).

In this regard, Liburd and Christensen (2013) discuss the design of teaching and learning activities with web 2.0 in International Tourism and Leisure management at University. They mention how the use of web 2.0 tools and teaching methods meet new student demands and how curricula are being adapted to this new form of teaching and technological philosophy.

However, some authors present failed cases, providing an opportunity to learn from the mistakes made. For example, Cole (2009) describes an experiment using wiki technology as a support in student learning and she concludes that the wiki had little impact on student engagement. However, this author suggests that students expressed curiosity about the technology, but that the course design was unattractive, a clear example of how student incentive and pedagogical design can affect their motivation. Afifi (2011:371) also comments on the appropriateness and applicability of e-learning, highlighting the need for research into how students perceive its advantages and disadvantages.

Sigala (2002) evaluates the evolution of internet pedagogy in order to identify effective e-learning for tourism and she confirms the benefits of on-line collaborative and constructive learning models, and the importance of internet pedagogical potential. This author suggests that further research is required in the design and implementation of these models, and that there is a need to move on from educational paradigms.

Given the global influence of connecting with technology, Costen (2009) explores the use of virtual learning environments (VLE), and tools used in hospitality management programmes in order to 
supplement traditional classroom instruction. This author argues that technology provides a tool which will encourage students to remain connected to their courses.

Regarding the use of wikis and blogs, Cobanoglu (2006) analyzed how the blogs used as a teaching tool were perceived by hospitality management students. According to this author a majority of students found the task of creating blogs easy and they also found them effective in their learning processes. Lillo-Bañuls and Fuentes (2011) analysed use of a wiki and a blog as educational tools for Tourism Diploma students. As a result they found that these technologies enabled students to contribute and provide feedback of learned content. The main effect was the time that students spent on reviewing the topics in the subject in order to upload their contributions on the wiki and blog. They also contrasted the improved academic performance of the student group actively using the wiki and blog. In addition, Liburd and Christensen (2013) affirm that virtual tools, such as wikis and blogs, provide an opportunity for students to express themselves regarding academic topics and to respond to other students' opinions and interpretations.

In global terms, Sheldon, Fesenmaier and Tribe, (2011:3) argue that the challenges facing the tourism industry and tourism educators call for a new paradigm of tourism education, Tourism Education Futures Initiative (TEFI). These authors argue that we need to re-think and re-design our tourism courses, thus changing students 'experiences.

In recent years a technological-social "revolution" has been taking place, arising from the mass use of new ITCs (Internet use in our daily lives, proliferation of social networks and their widespread use, especially prevalent among younger population segments, web search engines, mobile phones with Internet connection, iPod with connection, among others).

All these technological-social tools can be used by teaching staff, partly to motivate students and to facilitate their learning processes, and partly to assist in developing technological skills as a transversal 
axis in the teaching-learning processes. In order to achieve this, a positive attitude to the use of these new technological resources is essential, together with the possibility of applying and incorporating them in the teaching process, not only on the part of the lecturers involved, but also the students who will be using them frequently.

\section{3.-WIKI AND BLOG AS TECHNOLOGICAL EDUCATIONAL TOOLS IN THE SUBJECT OF TOURISM ECONOMICS}

Teachers are required to play a dynamic role in the use of methodological research strategies and to consider teaching as a continuous process of feedback from students, which will help to improve subject content. In this regard, Kim and Davies (2014:13) highlight the importance of stimulating students' motivation for self-directed learning in the development of content structure, peer interactions and student reflection on their learning process.

The role of lecturers is no longer confined to simply transmitting content and facts (Noteborn et al 2014). They are now required to manage their students' learning process, based on their autonomous work, which is directed and organised by the team of lecturers through continuous assessment and the sequential evaluation of the objectives achieved and competences acquired. In this regard, De Miguel (2006) indicates that the European Higher Education Area (EHEA) guidelines determine the central element of planning of a teaching topic or subject and should present the whole series of activities and tasks to be carried out sequentially in order to guide the experiences that the students will encounter throughout the teaching-learning process. As a result, this model will focus on the competences acquired by the student. The innovative concept here is similar to the so-called "constructive alignment" principle, in which forms, teaching methods and assessment systems are defined in a simultaneous and integrated way in relation to the competences or objectives to be obtained (Biggs, 2005). 
Sigala, 2002 and 2007; Costen, 2009; Liburd and Christensen (2013), among others, suggest that improving the quality of teaching and interaction with students, based on educational technological tools would be a positive development. The use of tools such as the blog and the wiki in this educational approach could act as a stimulus to students and a support for teaching staff (Cobanoglu, 2006; LilloBañuls and Fuentes 2011).

In the context of these innovative approaches, new virtual tools and technological-educational resources could be extremely useful in improving the teaching-learning process in the subject "Introduction to Economics", details of which are given below, a core subject of the first year of the Tourism Diploma . As described, the subject provides an introduction to economic analysis placing particular emphasis on tourism.

The subject is designed to introduce students to economic analysis by teaching the basic economic concepts and instruments necessary for them to understand not only general economic processes, but also those specific to the tourism sector, within the scope of economic theory and applied economics. The teaching plan outlines the following goals:

- to create student's awareness of the principal elements of economic reality and how theoretical concepts can be applied in order to understand the tourism sector.

- to equip students with the specific tools for correctly contextualising tourism activity within a methodology of economic analysis.

- to cultivate students' analytical and reasoning capacity, preparing them to deal real problems deriving from the relation between economic approaches and tourism activity.

- to foster a critical and rigorous attitude in students with respect to information received, so that they realise that economics does not necessarily have only one explanation, and that conversely, there are different approaches to explaining economic phenomena and the effects that they have on the tourism sector. 
- To stimulate students' intellectual capacity so that they will be able to read and interpret statistical sources and publications in the field of tourism economics, and understand and explain, in general terms, economic phenomena and their impact on the evolution of tourism activity.

- To encourage students to reflect on how economic phenomena are approached and the repercussions that they may have on the development of the tourism sector and how this will affect individuals and businesses involved in that sector.

By the end of the year, students should have developed their capacity to synthesize and interpret the information received, using the appropriate techniques to formulate explanations reflecting the complex nature of economic relationships in the tourism sector. The topics taught in these subjects (the tourism system, products and resources and tourism economics, tourism service supply and demand, market structure and competitive forms of tourism; public intervention and tourism policy) and the objectives and assessment may be consulted in the Open Course Ware (OCW) of the University of Alicante (Lillo-Bañuls, 2011).

In line with this purpose, the lectures in this subject have been developed along technologicaleducational research lines. Following the guidelines of the teaching innovation groups, based on virtual and new ICTS, the introduction of free software, full availability of homogenised online materials, complete use of technological resources for teaching available on the Virtual Campus (a complementary service to the teaching, academic management and administrative services in an Internet environment directed by the teaching staff, students and the administrative staff of the University of Alicante), through the Virtual Campus, students are able to access all the services provided by this tool, and the teaching option enables students to interact with lecturers: bibliography on the subject; resources, videos and web links established by the lecturer, tutorials and frequently asked questions, lecturer information, debates, tests and qualifications, etc) and use of diverse complementary technological tools ( such as wiki and blog, among others). 


\subsection{Blog and wiki}

In general terms, a blog can be defined as a website in which texts, comments or articles, usually written by one or several authors, are compiled on a regular basis. About wiki is a website containing pages which can be edited by multiple participants and in which a shared text can be created, amended or deleted. Wiki is an editable website created incrementally by visitors who collaborate on content (Cole, 2009: 142). The wiki becomes a collaboratively expandable collection of interlinked web pages, a hypertext system for storing and modifying information (Sigala 2007:636).

The students used a wiki and a blog to make their own contributions to different topics contained in the syllabus. In order to develop these contributions, both as individual assignments and as group projects, the blog contributions (http://blogtur.crearblog.com/) were carried out in groups, while the wiki contributions (http://gitetur.wikispaces.com) were made individually. In order to clearly establish what type of information should be provided and which issues should be addressed, a series of guidelines was posted for students in the virtual campus materials folder which they use regularly. Through the virtual campus resources, the teachers added an assignment proposal. The students were able to undertake an assignment, preparing and presenting of one of the following alternative options:

- Blog: Issues relating to economics and tourism were addressed in the blog so that the students made their blog contributions with respect to these specific topics: 1) Analysis of the tourism demand among university students: level of disposable income, frequency, distribution channel used, reasons for travelling, etc,: 2) Is tourism a necessity or a luxury that depends on income flexibility? 3) Examples of the Veblen effect in tourism: enumeration and explanations. Also, the students uploaded comments about a news item from the media (preferably digital media format which may be uploaded to the blog in the news link) related to one of the topics of the economics course and the tourism sector. The piece and how it related to the economics topic was explained in the blog. 
- Wiki: According to the teaching staff guidelines, the wiki was used to compile the students' contributions to the different topics in the syllabus of this subject. These were classified in different pages created by the teachers for each specific topic studied, grouping together the students' contributions. In particular, the students prepared a conceptual map of one of the topics from the programme or part of one of the topics previously agreed with the lecturer.

The possible future use of Moodle as a complement to the virtual campus is worth noting, as well as social networks such as Ning or LinkedIn which would enable groups of students to work privately, while also supervised by the teacher, with the appropriate contributions and debates taking place on this network.

\section{4.-PROFILES OF STUDENTS EMBARKING ON A TOURISM DEGREE, FAMILY} BACKGROUND AND ATTITUDINAL USE OF ICTs

Students' attitudes to the use of new technologies, the profiles for undertaking tourism studies and family background were questioned in a survey with 77 respondents conducted after the students had completed the economic subject corresponding to first year tourism degree groups, and one group of the second year tourism diploma course 2010/2011. A future task would be to create a survey that could be completed via the web platform which would enable those students who do not attend class regularly to participate.

Most students are already familiar with technological tools because, increasingly, they have access to internet using tablets, laptops, and smart phones, which are commonly used to search for information with frequent use made of wiki sites such as Wikipedia and other blogs.

In terms of distribution by gender, 26 survey respondents were men (33.73\%) and 51 were women $(66.23 \%)$. In terms of age, as expected, there was a greater preponderance of students aged between 
18 and 25, representing almost 90\%, with fewer students over 25 years $9.09 \%$ between 26 and 35, and $1.30 \%$ over 36 years of age).

\subsection{1.-Profile of students admitted to tourism studies.}

The results of the survey reveal that on the whole, students were admitted to tourism studies having studied the humanities and social science option in the second year of secondary school (baccalaureate) (61\%), followed some way behind by students who took the science and technology option baccalaureate $(14.47 \%)$. Professional training and others (over 45 years of age) represent $20 \%$ of the sample, equally distributed, and those tourism students who studied the arts option at secondary school were in the minority, representing, to date, less than $4 \%$ of the sample. The contingency table shows that this pattern of behaviour for accessing tourism studies is similar for men and women, as there were no significant differences between the two sexes.

\subsection{2.-Technological skills in Internet use.}

One of the main objectives of the study was to determine the technological skills used on Internet, obtained by asking about the frequency and intensity with which the student connected to the Internet, the resources used, and the purpose for which those resources were used.

The data reveals that a majority of students (86\%) use the Internet several times a day and practically all of them go online at least once a day, with men and women showing identical patterns with respect to the number of times that the students connect to the Internet. Regarding intensity, the highest frequency was recorded for those connecting for more than 3 hours a day (33.73\%), followed closely by those who connect for 1 to 2 hours a day (25.97\%), while a scant $6 \%$ of the sample go online for less than 30 minutes a day. There are no statistically significant differences (Chi square tests of 1.66, p-value 0.89 ) between the sexes with regard to intensity of use. 
Considering the use made of this tool by students, the Internet is mainly used for consulting the virtual campus (100 per cent of students), for reading and sending emails (92.21\%) -there is a statistically significant difference at $10 \%$ confidence level between men and women relating to this use -, exchanging files $(89.47 \%)$ and participating in forums and social networks $(92.71 \%)$ while students use chats less frequently (64.94\%). With respect to those tools designed for educational purposes by the subject heads, the survey reveals that their use by the students is significantly lower than those previously mentioned, with Wikipedia being used by $71.43 \%$ of students, and the participation in blogs (apart from the subject blog) is much lower at $31.17 \%$. The use of the wiki was similar for men (69.2\%) and women $(72.5 \%)$, while in the case of the blog, women use it slightly more $(35.3 \%)$ than men (23.1\%), but this difference is not statistically significant. In accordance with the proposals defined in the aforementioned qualitative analysis, these data may raise consideration of blogs in general as a student-friendly educational tool and the need to transmit knowledge through platforms with which students are more familiar, such as social networks.

(Table one about here)

The vast majority of students use the Internet at university $(80.52 \%)$, in their homes $(94.81 \%)$ and less frequently, in the library (64.94\%). Obviously, the frequency with which students use the Internet in their workplace is much lower $(19.74 \%)$ and in other places $(32.89 \%)$. With regard to the purpose of Internet use by tourism students, the main reason was for studying (100\%), but also for friendship (88.31\%), followed by perusal of information or newspapers $(77.92 \%)$, leisure or games $(69.74 \%)$ and other uses (61.84\%). There are no statistically significant differences in behaviour between men and women in these aspects.

4.1.3.-Academic history and its relationship with the use of technological tools for learning. 
A series of questions sought to relate students' academic background to the use and frequency of use of the Internet and their evaluation of the technological teaching tools implemented during the year. An analysis of the responses to these questions revealed that the majority of the students $(72.73 \%)$ studying tourism had not repeated any years of their previous academic studies (baccalaureate or Professional Training). The percentages were practically identical for men and women. Of the $27.27 \%$ of students who did repeat their studies, most had only repeated one academic course $(70.83 \%)$. The average grade obtained for the final year of the previous academic studies confirmed that tourism students belonged to the average scoring group with an average grade of between good and very good. More specifically, $46.68 \%$ of students obtained "good" while $36.84 \%$ obtained "very good". The two extremes of the scale are less frequent, as a scant $4 \%$ of students obtained an "outstanding" or “distinction" grade and 10.53\% obtained a "pass" grade. In this respect a clear pattern can be observed between men and women, with the latter obtaining a higher average grade (44 per cent of women obtained a "very good" score) than men (only $23 \%$ obtained a "very good" average grade), while the frequency of pass grades among men (19.2\%) was considerably higher than for women (6\%). Although these differences are not statistically significant (Chi square 5.64 p-value 0.22 ), the difference between sexes (effect size) is very clear.

A question on the performance of the students during the previous academic year was also included. The results showed that the majority $(68.79 \%)$ of students who responded $(n=70)$ passed all the subjects in June, $20 \%$ passed some subjects in September and $11.43 \%$ still had not passed some subjects.

\subsection{4.-Extra time spent on the subject.}

The time spent at home each day on carrying out projects and practical exercises of the subject was between 1 and 2 hours (40.26\%) for the majority of students or between 2 and three hours $(23.38 \%)$. 
With respect to the two extremes of the scale, approximately $20 \%$ claimed that they spend less than 1 hour a day on the subject and another $16 \%$ say that they dedicate more than 3 hours of their time each day to it. Again, statistically significant differences (Chi square test of 9.5 with p-value of 0.05 ) in behavioural patterns can be observed between men and women, with men dedicating less time than women to the subject. The survey was conducted among students who attended both the theoretical classes $(96.1 \%)$ and practical classes $(88.31 \%)$ regularly.

(Table two about here)

With respect to grants, $37.5 \%$ of those who responded the question $(\mathrm{N}=72)$ were found to have received some type of study grant. However, unlike student gender, this factor was not found to affect the time spent on studying the subject at home.

Tourism students do not require the support of private classes or extra tuition; given that $84.42 \%$ claimed that they did not attend any type of backup class.

\subsection{5.-Family educational background.}

Another group of questions sought to determine the family educational backgrounds of students in order to assess whether the family environment conditioned attitudes towards the use and evaluation of new technologies as a teaching tool.

The responses regarding the level of parents' schooling revealed that the majority of students come from families where parents do not have any education or only primary education.

(Table three and graph 1 about here) 
The students considered the job position held by their parents to be appropriate to their level of education, although in the case of their mothers, a significant percentage had a higher level of education than that required for the job that they perform.

Those students who had older brothers and/or sisters $(\mathrm{N}=44)$ were asked about the level of education that they had obtained or were in the process of studying. The results reveal a predominance of those studying at university level (54.55\%).

\subsection{6.-Evaluation of the technological teaching tools proposed. The wiki and the blog.}

Evaluation of the technological tools was framed through a question with the possibility of answering with a Likert scale ordinal categorical variable (0-5) for each of the items evaluated, where 5 was the maximum possible score. Assuming a continuous structure in the latent variables which would give rise to observed discrete responses, the results obtained were presented with the arithmetic mean, the median and the standard deviation of each of the elements.

The responses showed that the students gave an intermediate score to the tools used to improve their learning of the subject with average values in all cases. The highest average obtained was in the evaluation of the wiki as a tool to facilitate learning (2.84), while the lowest value corresponded to the wiki format (2.28). In both cases of wiki and blog evaluation, there were statistically significant differences in gender, with women (median 3) placing a higher value than men (median 2) on both tools. In general, it seems that the predisposition to use the tools proposed was favourable (scores slightly higher than the average for items regarding participation), although the students considered that the tools format could be improved to make them more attractive and helpful to the learning process. In the light of the results obtained, the possibility of offering content and teaching interaction through alternative communication channels such as social networks should not be ruled out. Today's students are more likely to participate through these channels than through the more traditional channels such as the blog or the wiki. 
(Graph 1 and Table four about here)

4. Qualitative analysis of the student opinion survey

In order to reinforce the considerations on application of new technologies to teaching and learning processes, free response questions were included in the survey for qualitative analysis. Thus, given the open nature of the responses (19 answers), any additional opinion supplied by the students that could give a deeper insight into their experience and their degree of involvement with the educational technology represented an opportunity to enhance the conclusions.

The qualitative analysis enabled common factors in the responses of students and revealed the overall idea that their participation in the project was positively received and satisfactorily utilised from the point of view of their own learning process. Another interesting result was their motivation to continue using similar methods in the future, which, when stored in their subconscious, may be used to their own benefit.

The free responses (19 answers) included in the survey were analysed through the use of the qualitative analysis program ATLAS 6.1.1., in order to capture information regarding the individual experiences of each student. More specifically, it reveals whether participating in the creation of the wiki and the blog, from their point of view, represented a significant help in their education in terms of both their learning and their desire to collaborate in similar experiences in the future. Furthermore, given the open nature of the responses, any additional opinion supplied by the students that could give a deeper insight into their experience and their degree of involvement with the educational technology represented a unique opportunity to enrich the conclusions. 
In order to analyse the information provided by the students, the responses were coded in accordance with the knowledge that the teaching staff had regarding the experience of their students, based on conversations with them and comments made throughout the academic year. Furthermore, other categories were created depending on the type of responses that were generated by the students in the surveys.

A total of 19 categories were created, which in turn were aggregated into four large explanatory groups of the issue in question.

The first group was called "Incentive to study" which had the most numerous responses with 75.34\% of interviewees providing answers, admitting that, in one way or another, the wiki and the blog represented a special incentive to revise what they had learned during the year and to incorporate new information referring to specific aspects that they were most interested in.

The second explanatory group was called "Enjoyable learning". In this case, the students (67.41\%) acknowledged that through this type of activity involving discussion, group work and collaboration, they were able to reinforce their knowledge and expand on it in an enjoyable way without becoming bored. In this way, the assimilation process became an activity that was a pleasurable process for them, replacing the laborious effort of solitary learning.

The third series of opinions were grouped under the title "Educational economies of scale" referring to the fact that a group of the surveyed students $(68,09 \%)$ acknowledged that the wiki and the blog not only helped them to revise and acquire knowledge in the subject but also introduced them to new technological resources that were previously unknown to them. In this way, as well as improving their 
level in Economics, they also acquired new skills related to the use of technological tools and the search for information on the Internet.

Finally, the last group was called "Motivation", including opinions that acknowledged the fact that the use of the two types of educational technology tools object of this study induced a desire in students to use similar learning instruments in the future $(45.38 \%)$. Therefore, this shows that these tools not only provided them with educational support at the time of using them, but their satisfaction with the results generated a high level of interest in using them again in the future for the same purpose. In fact, the students who did not give any opinion to this respect, did not express any objections to them but suggested other types of additional tools that could complement the use of the wiki and the blog in the classroom, such as video streaming, videos, or even social networks such as Facebook or LinkedIn in which to form discussion groups related to issues that the students suggested themselves with the opportunity of interacting with students from other universities.

In short, the qualitative analysis enabled common factors in the responses of the students to be identified, which, once organised into groups revealed the overall idea that their participation in the project was positively received and satisfactorily utilised from the point of view of their own learning process. And, maybe more importantly, the responses of the students revealed their motivation to continue using similar methods in the future, which when stored in their subconscious may be used to their own benefit.

\section{DISCUSSION}

\section{5.-CONCLUSIONS AND RECOMMENDATIONS}

The application of new technology to higher education is unquestionably an essential element for improving the teaching-learning processes in our universities. Furthermore, its widespread use enables 
students to improve their technological dexterity and skills for which there is a growing demand in our society.

In this study we have analysed the use of the blog and the wiki as educational resources in teaching the Tourism Degree, seeking to evaluate the attitude of the students towards this new component proposed by the subject lecturers and assessed as part of the overall grades.

It was found that the wiki and the blog were well received and they were used by the students.

From a quantitative point of view, the results reinforce the qualitative impressions expressed by some students. Therefore, these results appear to confirm the suitability of the blog as a student-friendly educational tool and the need to transmit knowledge through platforms with which students are more familiar, such as the social networks.

Generally speaking, it seems that the students are favourably predisposed towards the tools proposed (scores slightly higher than the mean in the items referring to participation), although the students consider that the tool formats could be improved to make them more attractive and helpful to the learning process. In light of the results obtained, the possibility of offering teaching content and interaction through alternative communication channels such as social networks should not be ruled out. Today's students are more inclined to participate through such channels, rather than through the blog or the wiki used to date. However, the adoption of new teaching-learning methods including information and communication technologies has enabled students studying economics as part of their the tourism degree to contribute and provide feedback of the knowledge gained both with their teachers and with their fellow students, through the use of the blog and the wiki accessed via the Internet. This type of technological-educational instrument facilitates continual reinforcement of the course content and the participation of students, the majority of whom are extremely familiar with ICTs. 


\section{REFERENCES}

Afifi, G. (2011) E-learning as an alternative stratefy for tourism higher education in Egypt. Qualitity Assurance in Education 19:357-374.

Biggs, J. (2005) Calidad del aprendizaje universitario. Madrid. Narcea.

Buhalis, D \&Law, R. (2008) Progress in information technology and tourism management: 20 years on and 10 years after internet- The state of eTourism research. Tourism Management 29:609623

Cobanoglu, C. (2006) An analysis of Blogs as a Teaching Tool as Perceived by Hospitality Management Students. Journal of Hospitality, Leisure, Sport \&Tourism Education 5 (2): 8388 .

Cole, M. (2009) Using wiki technology to support student engagement: Lessons from the trenches Computers \& Education 52:141-146

Costen, W.M. (2009). The value of staying connected with technology: An análisis exploring the impact of using a course management system on student learning. Journal of Hospitality, Leisure, Sport \&Tourism Education 8 (2):47-59.

De Miguel, M. (2006) Metodologías de enseñanza y aprendizaje para el desarrollo de competencias. Madrid. Alianza editorial.

Fuentes-Pascual, R. \& Lillo-Bañuls, A. (2011). Nuevos métodos tecnológico-educativos en la economía del turismo", Papers de Turisme 49-50: 77-87.

Kim, A.K. \& Davies, J. (2014) A teacher's perspective on student centred learning: Towards the development of best practice in an undergraduate tourism course. Journal of Hospitality, Leisure, Sport \& Tourism Education 14:6-14.

Liburd, J.J. \& Christensen, I.F. (2013) Using web 2.0 in higher tourism education. Journal of of Hospitality, Leisure, Sport \& Tourism Education 12: 99-108.

Lillo-Bañuls, A. (2009 ) El papel del capital humano en el sector turístico: algunas reflexiones y propuestas. Cuadernos de Turismo 24:53-64.

Lillo-Bañuls, A. (2009b). Human capital and its role in the tourist sector: Some reflections and proposals. Cuadernos de Turismo 24: 243-248.

Lillo-Bañuls, A. (2009c) El Capital Humano Como Estrategia Competitiva en el Sector Turístico Español. IV International prize on touristic studies Gabriel Escarrer, Cátedra Sol Melia. Universidad de Islas Baleares, Edicions UIB.

Lillo-Bañuls, A. (2011) Introducción a la economía. Turismo, License Creative Commons , Octubre 2007, http://ocw.ua.es/Ciencias_Sociales_y_Juridicas/introduccion-a-la-economia-grupo-Openware Course $1 /$ Course_listing 
Noteborn, G., Dailey-Herbert, A., Bohle Carbonell, K. \& Gijselaers, W. (2014) Essential Knowledge for academic performance: Educating in the virtual world to promote active learnin. Teaching and Teacher Education 37:217-234

Sheldon, P.J., Fesenmaier, D.R. \& Tribe, J. (2011) The Tourism Education Futures Initiative (TEFI): Activating Change in Tourism Education. Journal of Teaching in Travel \& Tourism 11:2-23

Sigala, M. (2002). The evolution of Internet pedagogy: Benefits for tourism and Hospitality education, Journal of Hospitality, Leisure, Sport \& Tourism Education, 1(2): 29-45.

Sigala, M.( 2007). Integrating Web 2.0 in e-learning enviroments: a socio-technical approach, International Journal of Knowledge and Learning, 3(6): 628-648.

Volman, M. (2005) A variety of roles for a new type of teacher Educational technology and the teaching profession. Teaching and Teacher Education 21:15-31. 


\section{APPENDIX: SURVEY}

1.-Sex: A [Male] B [Female]

2.-Age: A [18-25] B [26-35] C[ 36-45] D [Over 45]

3.-Accessed University from:

A [secondary school Bachillerato - arts]

B [secondary school Bachillerato - science and technology]

C [secondary school Bachillerato - humanities and social sciences]

D [Vocational Training -FP]

$\mathrm{E}$ [Others, over 24, 40 or 45 years of age, $\mathrm{COU}$ (former university preparation course), etc.]

Technological skills and Internet use:

4.-Number of times the student connects to the Internet

A [Several times a day]

B [5 - 7 times a week]

C $[2-4$ times a week]

D [Once a week]

E [Less than once a week]

5.-Time spent using the Internet in minutes per day

A [Up to 30 minutes per day]

B [31-60 minutes per day]

C [61-120 minutes per day]

D [121-180 minutes per day]

E [More than 180 minutes per day]

Resource used -each one is a question-

6.-Virtual Campus A[Yes] B[No]

7.-E-mail A[Yes] B[No]

8.-Chat Yes[A] B[No]

9.-Wikipedia or other wikis apart from the tourism wiki of the subject $\mathrm{Yes}[\mathrm{A}] \mathrm{B}[\mathrm{No}]$

10.-Blogs apart from the tourism blog of the subject Yes[A] $\mathrm{B}[\mathrm{No}]$

11.-Exchange/Download of files Yes[A] B[No]

12.-Forums/Social Networks (Facebook, etc.) Yes[A] B[No]

Place where the student uses the Internet

13.-University $A[\mathrm{Yes}] \mathrm{B}[\mathrm{No}]$

14.-At home or homes of others $A[\mathrm{Yes}] \mathrm{B}[\mathrm{No}]$

15.-Library A[Yes] B[No]

16.-Workplace $A[\mathrm{Yes}] \mathrm{B}[\mathrm{No}]$

17.-Other A[Yes] B[No]

Purpose of using the Internet:

18.-Leisure, games $\mathrm{A}[\mathrm{Yes}] \mathrm{B}[\mathrm{No}]$

19.-Study A[Yes] B[No]

20.-Information, newspapers $A[\mathrm{Yes}] \mathrm{B}[\mathrm{No}]$

21.-Friendship $A[\mathrm{Yes}] \mathrm{B}[\mathrm{No}]$

22.-Other $A[\mathrm{Yes}] \mathrm{B}[\mathrm{No}]$

23.- With respect to his/her previous studies, has the student repeated any years during the secondary bachillerato or FP vocational training cycle?

$\mathrm{A}[$ Yes] 
$\mathrm{B}[\mathrm{No}]$

24.- If the previous answer was "yes":

A [He/she repeated one year]

B [He/she repeated more than one year]

25.-With respect to the last academic year:
a) The student passed all the subjects in June
b) The student passed some of the subjects in September
c) The student has still not passed all the subjects

26.-What was the student's average grade in the last year of secondary school "bachillerato"?
a) Distinction or outstanding
b) Very good
c) Good
d) Pass

27.-How much time does the student spend at home each day on the projects and practical exercises of this subject?
a) Less than one hour
b) Between one and two hours
c) Between two and three hours
d) Between three and four hours
e) More than four hours

28.- Does the student attend the theoretical classes of this subject regularly?
a) On the whole attends regularly
b) Misses quite a few classes
c) Does not attend

29.- Does the student attend the practical classes of this subject regularly?
a) On the whole attends regularly
b) Misses quite a few classes
c) Does not attend

30.-Does the student receive any study grants?
a) Yes
b) No

31.-Does the student receive private classes or attend any complementary teaching centres such as an academy?
a) Yes
b) No

32.-In relation to the education of the student's father:
a) Did not complete basic education (no education)
b) Completed primary education (basic education)
c) Completed secondary education, bachillerato or FP vocational training
d) Has a university diploma (teaching, technical engineering, nursing, etc.)
e) Has a university degree (graduate, engineer or architect).

33.-Does the student consider that his/her father is working in a job that is:
a) appropriate to his training and education (appropriately educated)
b) beneath his training and education, that is, he is working in a job that requires a lower level of training than he has (over-educated)
c) above his training, given his experience and performance he occupies a position for which a higher level of training is usually required (under-educated).

34.- In relation to the education of the student's mother: 
a) Did not complete basic education (no education)

b) Completed primary education (basic education)

c) Completed secondary education, bachillerato or FP vocational training

d) Has a university diploma (teaching, technical engineering, nursing, etc.)

e) Has a university degree (graduate, engineer or architect).

\section{5.- Does the student consider that his/her mother is working in a job that is:}

a) appropriate to her training and education (appropriately educated)

b) beneath her training and education, that is, she is working in a job that requires a lower level of training than she has (over-educated)

c) above her training, given her experience and performance she occupies a position for which a higher level of training is usually required (under-educated).

36.-(Only if the student has older brothers and/or sisters). The level of education that they have obtained or are currently studying (in the case of more than one sibling where each has studied or is studying a different course, mark the option corresponding to the sibling who has studied / is studying the highest academic level):
a) Has not completed basic/primary education
b) Completed basic/primary education
c) Secondary schoolBachillerato
d) FP vocational training
e) Has completed or is studying a university education

\section{Score of 0 to 5 (where 5 is the maximum score)}

\begin{tabular}{|c|c|}
\hline 37. & $\begin{array}{l}\text { Evaluate, from } 0 \text { to } 5(0=\mathrm{A}, 1=\mathrm{B} \text {, } \\
2=\mathrm{C}, 3=\mathrm{D}, 4=\mathrm{E}, 5=\mathrm{F}) \text {, how participating in } \\
\text { the wiki has helped your learning process. }\end{array}$ \\
\hline 38. & $\begin{array}{l}\text { Evaluate, from } 0 \text { to } 5(0=\mathrm{A}, 1=\mathrm{B} \text {, } \\
2=\mathrm{C}, 3=\mathrm{D}, 4=\mathrm{E}, 5=\mathrm{F}) \text {, how participating in } \\
\text { the blog has helped your learning process. }\end{array}$ \\
\hline 39. & $\begin{array}{l}\text { Evaluate, from } 0 \text { to } 5(0=\mathrm{A}, 1=\mathrm{B} \text {, } \\
2=\mathrm{C}, 3=\mathrm{D}, 4=\mathrm{E}, 5=\mathrm{F}) \text {, the format of the } \\
\text { wiki. }\end{array}$ \\
\hline 40. & $\begin{array}{l}\text { Evaluate, from } 0 \text { to } 5(0=\mathrm{A}, 1=\mathrm{B} \text {, } \\
2=\mathrm{C}, 3=\mathrm{D}, 4=\mathrm{E}, 5=\mathrm{F}) \text {, the format of the } \\
\text { blog. }\end{array}$ \\
\hline 41. & $\begin{array}{l}\text { Evaluate, from } 0 \text { to } 5(0=\mathrm{A}, 1=\mathrm{B} \text {, } \\
2=\mathrm{C}, 3=\mathrm{D}, 4=\mathrm{E}, 5=\mathrm{F}) \text {, the extent to which } \\
\text { you believe the wiki to be a good idea.. }\end{array}$ \\
\hline 42. & $\begin{array}{l}\text { Evaluate, from } 0 \text { to } 5(0=\mathrm{A}, 1=\mathrm{B} \text {, } \\
2=\mathrm{C}, 3=\mathrm{D}, 4=\mathrm{E}, 5=\mathrm{F}) \text {, the extent to which } \\
\text { you believe the blog to be a good idea. }\end{array}$ \\
\hline
\end{tabular}




\begin{tabular}{|c|l|}
\hline 43. & $\begin{array}{c}\text { Would you like to continue } \\
\text { participating in other wikis in the future? } \\
(0=\mathrm{A}, 1=\mathrm{B}, 2=\mathrm{C}, 3=\mathrm{D}, 4=\mathrm{E}, 5=\mathrm{F})\end{array}$ \\
\hline $\mathbf{4 4 .}$ & $\begin{array}{c}\text { Would you like to continue } \\
\text { participating in other blogs in the future? } \\
(0=\mathrm{A}, 1=\mathrm{B}, 2=\mathrm{C}, 3=\mathrm{D}, 4=\mathrm{E}, 5=\mathrm{F})\end{array}$ \\
\hline $\mathbf{4 5 .}$ & \begin{tabular}{|} 
To what extent do you believe that \\
the wiki has made the subject more \\
appealing? $(0=\mathrm{A}, 1=\mathrm{B}, 2=\mathrm{C}, 3=\mathrm{D}, 4=\mathrm{E}$, \\
$5=\mathrm{F})$
\end{tabular} \\
\hline $\mathbf{4 6 .}$ & $\begin{array}{l}\text { To what extent do you believe that } \\
\text { the blog has made the subject more } \\
\text { appealing? }(0=\mathrm{A}, 1=\mathrm{B}, 2=\mathrm{C}, 3=\mathrm{D}, 4=\mathrm{E}, \\
5=\mathrm{F})\end{array}$ \\
\hline
\end{tabular}

\section{BRIEFLY AND VOLUNTARILY RESPOND TO THE FOLLOWING QUALITATIVE} QUESTIONS ABOUT THE BLOG AND THE WIKI

A.-What type of technological instruments do you believe would be a good idea to incorporate in the classes apart from wikis and blogs?

B.- What would you change in the wiki and/or the blog to improve them? (With respect to the format, design, the method of participating, the issues addressed....everything in general...)

C.- What did you most like about the wiki? And the blog? (With respect to the format, design, the method of participating, the issues addressed....everything in general)

D.- What did you like the least about the wiki? And the blog? $i$ (With respect to the format, design, the method of participating, the issues addressed....everything in general)

E.-Any other suggestion, idea or observation that you would like to make 